\title{
ARTIGOS
}

\author{
CIDADE, HISTÓRIA E CULTURA
}

\section{AS CASAS DE CEILÂNDIA}

\author{
Elane Peixoto* \\ Adriana Mara Vaz de Oliveira ${ }^{* *}$ \\ Alana Silva Waldvogel* \\ * Universidade de Brasília, Faculdade de Arquitetura e Urbanismo, Brasília, DF, Brasil \\ ** Universidade Federal de Goiás, Faculdade de Artes Visuais, Goiânia, GO, Brasil
}

\section{Resumo}

Este artigo dedica-se ao morar em Ceilândia, a cidade-satélite com maior população do Distrito Federal. Ele remete à sua criação em 1970, com a transferência de 80 mil pessoas, vindas da Vila do IAPI. Essa transferência previa a construção de casas provisórias utilizando o material das casas desmontadas da vila referida e que, com o passar do tempo, seriam substituídas por casas de alvenaria. Passados cinquenta anos de sua criação, Ceilândia pouco remete ao seu início: não se limitou ao traçado original, novos bairros se somaram e suas primeiras moradias foram substituidas e alteradas, para permitir o ajuste às demandas das famílias. A pesquisa entende o morar em duas dimensões complementares: a cidade e a casa, por isso se dedica à história da cidade e, em seguida, às moradias de seus habitantes. Para abordar esses dois aspectos, foi entrevistado o urbanista responsável pelo projeto de Ceilândia, além de analisadas as narrativas de pioneiros disponíveis no Arquivo Público do Distrito Federal, bem como os depoimentos e desenhos de estudantes do Ensino Fundamental, coletados especialmente com o fito de esboçar um quadro do morar em Ceilândia.

Palavras-chave

Casa Ceilandense, Ceilândia, Cidade-satélite, Brasília (DF), História Urbana. 


\title{
ARTICLES
}

\section{CITY, HISTORY AND CULTURE}

\section{THE HOUSES IN CEILÂNDIA}

\author{
Elane Peixoto* \\ Adriana Mara Vaz de Oliveira ${ }^{* *}$ \\ Alana Silva Waldvogel* \\ * Universidade de Brasília, Faculdade de Arquitetura e Urbanismo, Brasília, DF, Brazil \\ ** Universidade Federal de Goiás, Faculdade de Artes Visuais, Goiânia, GO, Brazil
}

\begin{abstract}
This article is dedicated to living in Ceilândia, the satellite-city with the largest population in the Federal District. It refers back to when the city was created in 1970, and 80,000 people were transferred from the Vila IAPI Settlement. This transfer foresaw the construction of temporary housing by reusing material from the dismantled homes at the settlement, which, over the years, were replaced with masonry houses. Fifty years after its creation, Ceilândia bears little resemblance to its beginnings; it has not been constrained within its original layout; new neighborhoods have been added, and the original dwellings have been replaced and altered in order to adjust to the requirements of the families. This research understands living as being within two complementary dimensions: the city and the home. Thus, it is dedicated to the history of the city and, subsequently, to the homes of its residents. In order to address these two aspects, the urbanist responsible for the original Ceilândia project was interviewed, and narratives of the pioneers, held at the Federal District Public Archives, were analyzed, together with testimonies and drawings by primary school students, expressly collected with the aim of sketching a framework of living in Ceilândia.
\end{abstract}

Keywords

Ceilândia Houses, Ceilândia, Satellite city, Brasilia (DF), Urban History. 


\section{AS CASAS DE CEILÂNDIA}

Elane Peixoto

Adriana Mara Vaz de Oliveira

Alana Silva Waldvogel

Preâmbulo

O importante não é a casa onde moramos. Mas onde, em nós, mora a casa. Mia Couto (2003), Um rio chamado tempo, uma casa chamada terra.

Casa: duas sílabas nas quais se pode deparar com a imensidão do mundo. Sinônimo de lar, moradia, residência e habitação, o uso da palavra é de longa data. Nos primeiros séculos do Brasil Colônia, o termo traduzia-se por qualquer cômodo de uma morada. Com o passar do tempo, tornou-se nome composto para designar alguma particularidade: “casa assobradada”, “casa de farinha”. Antes do século XX, a palavra casa afirmou-se como o lugar de moradia de uma família, abrangendo diferentes tipos, pois toda casa é o viver sob um teto. Assim, usualmente, fala-se "a casa de alguém”, "chegar em casa”, "lá em casa”, "a casa é sua”, “ô de casa” (BRESCIANI, 2014), expressões designantes da vontade de compartilhar um mundo ou dele se apartar. Pode ser qualquer casa: aquela do passado, do presente ou ainda aquela sonhada.

\footnotetext{
1. As autoras agradecem à Fundação de Amparo à Pesquisa do Distrito Federal (FAP-DF), pelo financiamento da pesquisa, ao Arquivo Público do Distrito Federal, pelas consultas em seu acervo, e ao Centro de Ensino Fundamental 19 de Ceilândia, base de nosso trabalho de campo.
} 
Muito além de fisicamente mensurável ou morfologicamente reconhecível, a casa se coloca como entidade moral permeada de valores, códigos e emoções presentes na fala: “casa de bem”, “de respeito”, “moça de casa”. A casa é um mundo ordenado e protegido. Ela é sagrada (ELIADE, 1992), considerada um cosmos, uma vez que ordena o caos, o desconhecido, o inquietante. Curiosamente, esse espaço articula-se e, ao mesmo tempo, se opõe ao mundo da rua: à moça de casa antagoniza-se a mulher da rua (DAMATTA, 1991). Os modos de ler, falar e explicar o mundo são diferentes se a perspectiva é da casa ou da rua, mas ambas dizem a cidade, afinal: “[...] a casa, entre nós, ordena um mundo à parte. Universo onde o tempo não é histórico, mas cíclico, tempo que vive de durações que não se medem por relógios, mas por retratos amarelados e corroídos pelas traças [...]" (DAMATTA, 2001, p. 28). Sobreposição de tempos, a casa é um depósito de memórias para o qual contribuem suas dimensões - matéria/espaço, representação/imagem (BACHELARD, 1996).

Ao se afirmar assim, demarcamos a distinção que, aqui, é dada à casa, para escapar da superada batalha entre história e memória, que fecundou os debates do final do século XX. Essa batalha se deu entre autores que afirmavam a captura definitiva da memória pela história. A memória cativa só poderia, então, existir em lugares específicos, consagrados como seus. A posição assumida por este artigo é bem contrária, pois cremos, com Jeudy (2004), que a memória tem sempre uma espécie de coelho na cartola. Ela sobrevive do inesperado, das relações afetivas, de saltos temporais do passado no presente, executados com a elegância dos tigres (BENJAMIN, 1994; SEIXAS, 2001) - e que melhor lugar para essa mágica ocorrer senão no espaço da casa? Ela é artefato cultural que se liga às construções de um grupo e de suas partilhas. Ao modo de construir, aos materiais utilizados, à disposição dos ambientes, soma-se a forma como é usada - ao almoço servido no sofá da sala em frente à televisão, às brincadeiras proibidas no quarto, ao cheiro do sabonete vindo do banheiro... O modo de construir e usar a casa se entrelaça às representações que dela se constroem, como aconchego, segurança, conquista... Essas urdiduras, em maior ou menor grau, estão presentes na vida da grande maioria das pessoas.

\section{Introdução}

Neste artigo, ocupamo-nos das moradias de Ceilândia, cidade-satélite criada na década de 1970. O plano de Lucio Costa para a nova capital brasileira previa a expansão da cidade por meio da criação de cidades-satélites. Todavia, antes que o chamado Plano Piloto tivesse sido ocupado, essa categoria de cidade surgiu como consequência do fluxo migratório gerado pela construção de Brasília. As áreas próximas ao Plano Piloto foram ocupadas, de forma planejada ou espontaneamente, 
pelos construtores da capital, que projetaram acampamentos para seus empregados, profissionais graduados ou não.

As ocupações provisórias (acampamentos e assentamentos informais) acomodavam uma população que se acreditava temporária porque, com as obras concluídas, uma boa parte dela - um terço - supostamente voltaria a seus lugares de origem. Assim, apenas um terço dos migrantes permaneceria em Brasília, enquanto o outro terço deveria dedicar-se às atividades de agricultura no entorno do Plano Piloto (HOLSTON, 2010). Não foi o que aconteceu. As ocupações informais, em especial, mesmo em condições muito precárias, foram pontuando o território do Distrito Federal (DF). A solução encontrada foi a antecipação da criação das cidades-satélites. A primeira a marcar o mapa do DF foi Taguatinga, em 1958. Ela antecede o Plano Piloto em ocupação e soma-se aos acampamentos das construtoras e da Companhia Urbanizadora da Nova Capital (Novacap), constituídos pelo Gama e Cidade Livre, de cujo entorno surgiriam os assentamentos de trabalhadores (COSTA, 2011). Em 1965, eram oito as cidades-satélites; em 2019, contam-se 33, embora atualmente elas sejam designadas como Regiões Administrativas.

Na década de 1970, organizou-se a Campanha de Erradicação das Invasões (CEI), originando a cidade-satélite de Ceilândia, atual IX Região Administrativa do Distrito Federal, de cujas casas queremos falar. Ao entender a casa como a ordenação de um mundo à parte, acreditamos ser necessário discorrer sobre o que está além de sua soleira. Por essa razão, apresentamos Ceilândia, recuperando sua história e a saga de sua população durante a transferência para essa cidade. Em seguida, nós nos dedicamos a suas casas, assinalando as primeiras moradias, precárias e provisórias, a substituição delas por casas em alvenaria construídas segundo modelos-padrões e, por fim, as alterações que sofreram no decurso do tempo, com vistas a promover ajustes às demandas dos grupos familiares.

O corpus documental para atingir esses objetivos constitui-se de depoimentos do Programa de História Oral do Distrito Federal; de entrevista com Ney Gabriel, autor do projeto de Ceilândia; de levantamentos de campo de duas quadras do centro da cidade, a QNM 17 e a QNM 18, nas quais estão construídas setecentas habitações; de textos de estudantes do Ensino Fundamental, versando sobre suas moradias; além de desenhos por eles realizados sobre o mesmo tema. Com esse material, pretendemos alçar um nível de compreensão da cidade, de suas casas e de sua gente.

Na sequência, apresenta-se Ceilândia sob uma perspectiva histórica, ao mesmo tempo que se discutem suas moradias na sua dupla condição: de matéria e de representação. 


\section{Ceilândia e suas primeiras casas}

1.1 O Plano Urbano

Embora tenhamos partido do levantamento da situação atual das quadras QNM 17 e QNM 18 de Ceilândia para empreender um movimento em direção ao passado, este texto começa de forma cronológica com um histórico da cidade para melhor situar o leitor.

A criação de Ceilândia em 1970-71, situada a aproximadamente $30 \mathrm{~km}$ do Plano Piloto, deu continuidade a uma prática de acomodação de populações menos favorecidas em seu entorno, o que implicava a remoção de famílias para cidades-satélites nem sempre devidamente urbanizadas. O plano urbanístico da cidade é de autoria de Ney Gabriel, arquiteto urbanista dos quadros da Novacap.

Conforme entrevista concedida por $\mathrm{Gabriel}^{2}$, suas referências projetuais foram o Plano Piloto e o livro de urbanismo de Giorgio Rigotti (1955). A estrutura básica da cidade pode ser descrita pela proposição de dois eixos orientados segundo os pontos cardeais (norte/sul e leste/oeste) ao longo dos quais se organizam os módulos espaciais constituídos pelas unidades de vizinhança. A proposição do plano recorre a Rigotti, possivelmente, para as soluções técnicas, em particular para dimensionamentos.

Ney Gabriel observa que o livro do urbanista italiano era base para os profissionais de sua geração. Intitulado Urbanismo: la técnica (1947), ele foi concebido em duas partes, de acordo com o que o autor considerava próprio a esse campo de estudo. No volume constam 546 quadros ilustrativos organizados em quatro conjuntos relacionados às superfícies urbanas, a saber: de circulação, edificáveis, parques e jardins e serviços públicos. Com base em referências de várias cidades, Rigotti indica dimensões de vias, alinhamentos, tipologias de residências, hotéis, comércio, edifícios para culto, assim como áreas verdes e, por último, serviços de água potável, limpeza urbana, gás, iluminação.

A urgência em abrigar 80 mil pessoas, tarefa atribuída ao arquiteto da Novacap, credita um valor particular a esse livro, visto que a forma como as referências são apresentadas, semelhantes àquelas presentes no livro $A$ arte de projetar em arquitetura, do arquiteto alemão Ernst Neufert (1936), facilita a consulta de quem tem pressa em resolver as questões de um projeto de cidade. Os desenhos comunicam-se com facilidade, como se pode ver a seguir (Figura 1).

2. A entrevista foi concedida às autoras em 21 de maio de 2018. 

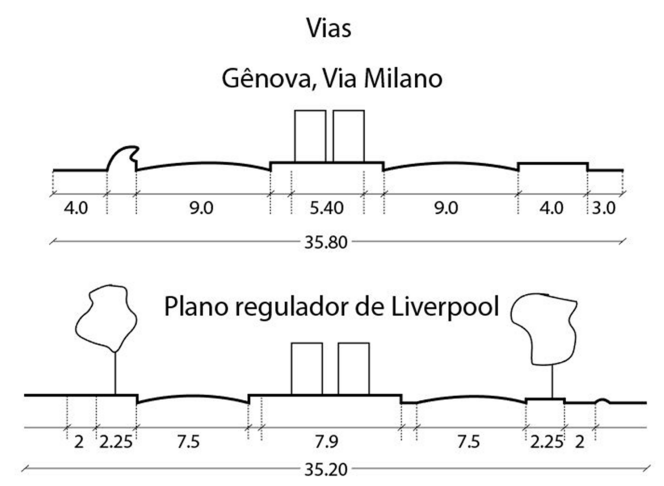

Paris, Boulevard Blanqui

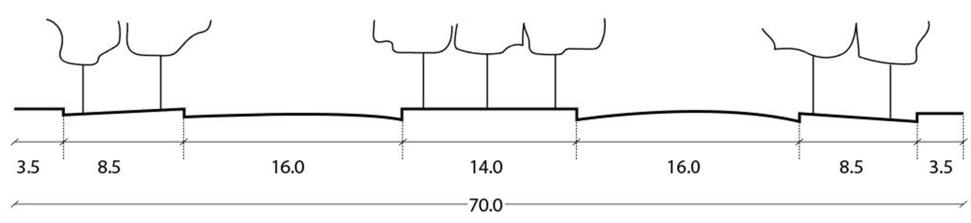

Figura 1. Vias de Gênova, Liverpool e Paris

Fonte: Redesenho de Alana Waldvogel com base no livro Urbanismo: la técnica, de Giorgio Rigotti, 1955.

O desenho de Ney Gabriel para Ceilândia ganhou um apelido: o núcleo pioneiro tornou-se conhecido por "barril”, em associação com sua forma. Estruturado pelos dois eixos mencionados, que se cruzam ortogonalmente, o plano define quatro faixas para loteamentos, totalizando quarenta quadras residenciais. As grandes áreas entre as faixas arqueadas do "barril" destinavam-se à implantação de equipamentos públicos e habitação, como atesta a planta original encontrada na Secretaria de Estado de Gestão do Território e Habitação (SEGETH, 2019). As Unidades de Vizinhança (UV), no centro de Ceilândia (o barril), são formadas por catorze linhas de residências, separadas em dois conjuntos de sete linhas por uma área institucional para a locação dos equipamentos - escolas, igrejas e comércios. Cada conjunto de sete linhas é formado por cinquenta lotes, totalizando 350 lotes e 700 no total da UV. Com faixas de loteamento longitudinalmente longas, a circulação do pedestre de uma faixa para a outra era dificultada. Para resolver o problema, Gabriel propôs um sistema de becos em quincunce, para permitir o movimento de pedestres no sentido transversal dos conjuntos (Figura 2).

A UV em Ceilândia é distinta daquela do Plano Piloto. O primeiro aspecto a diferenciá-las é o fato de que, no caso da segunda, as superquadras não são subdivididas em lotes - lembrando que o solo não é propriedade privada, mas pública. São ocupadas pelos blocos residenciais de seis pavimentos sobre pilotis, cada quatro superquadras constituindo uma UV. Além disso, as superquadras são cingidas por renques de árvores, em coerência com a intenção bucólica que Costa pretendeu dar à cidade. Em Ceilândia, não houve preocupação semelhante; as UVs são desprovidas de arborização, quase restrita à sua principal avenida. 
Ruas e calçadas estão sempre dimensionadas com tamanhos mínimos, permitindo cogitar que não só a urgência pesou sobre a concepção da cidade, como também os custos fundiários e de futura instalação de infraestrutura. Os perfis apresentados a seguir oferecem uma clara noção das diferenças entre as dimensões dos principais eixos do Plano Piloto e de Ceilândia (Figura 3).
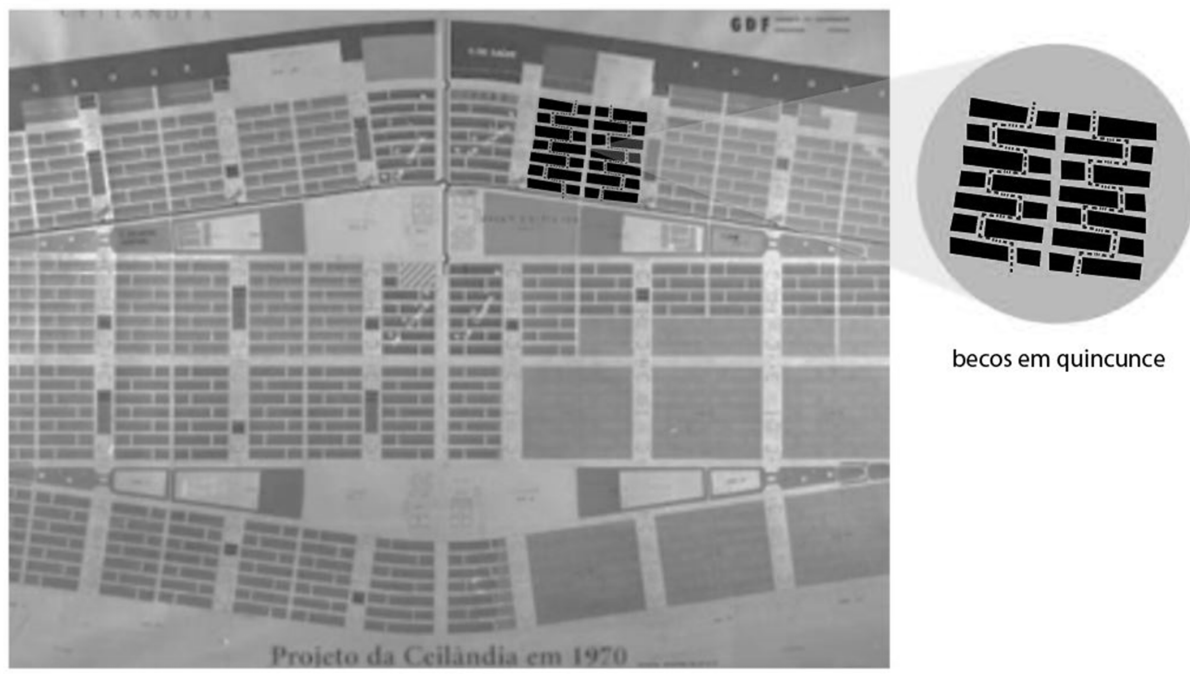

becos em quincunce

Figura 2. Becos em quincunce de Ceilândia

Fonte: Arquivo Público do Distrito Federal (2019), com destaques de Alana Waldvogel.

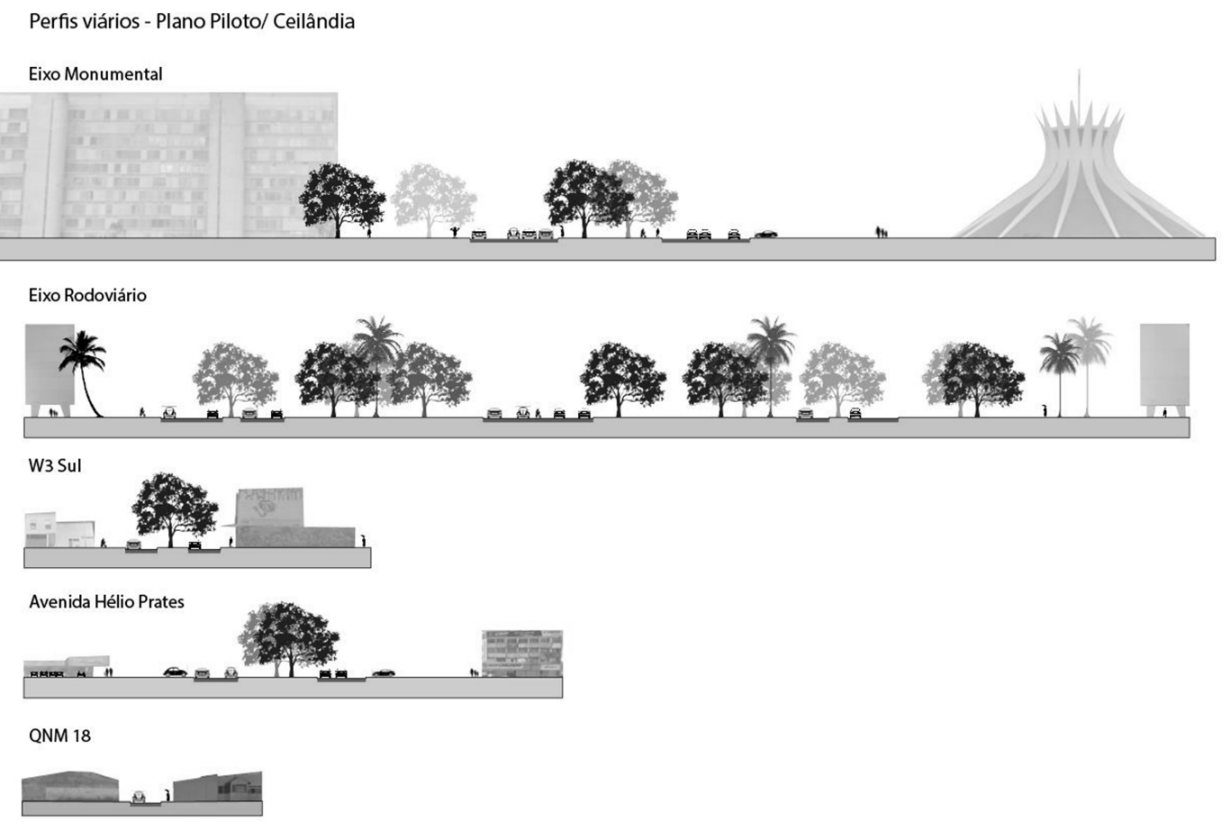

Figura 3. Perfis viários, Plano Piloto e Ceilândia Fonte: Alana Waldvogel. 
Nesses cinquenta anos, Ceilândia não parou de crescer e, com Taguatinga e Samambaia, constitui o mais importante polo de atração - conhecido por Taceisa - para novas urbanizações. A expansão surpreendente da cidade pode ser visualizada por meio da linha de tempo apresentada na forma de mapas (Figura 4).

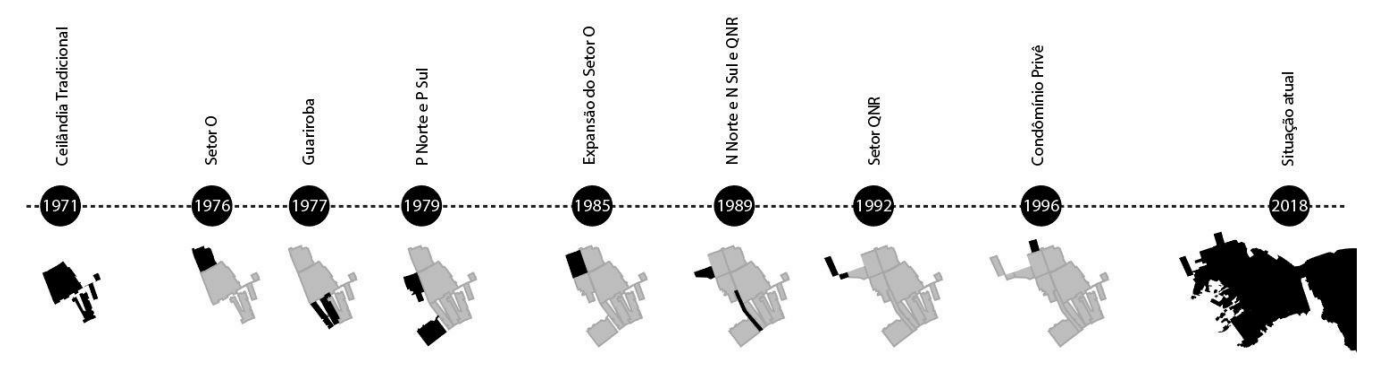

Figura 4. Evolução urbana de Ceilândia Fonte: Alana Waldvogel.

Foi nessa cidade, construída no Cerrado, onde o vento uiva e provoca redemoinhos de poeira, que 80 mil pessoas foram instaladas em pouco tempo. Vejamos como isso se deu, segundo os depoimentos dos primeiros moradores da cidade.

1.2 A remoção

Cerradão, mato, cobras, vento forte, chuvas infindáveis, famílias sob tetos de lona. Essas são as palavras e expressões recorrentes em muitos dos 24 relatos dos primeiros moradores de Ceilândia disponíveis no Arquivo Público do Distrito Federal (2019). Entre 27 de março de 1971 e 9 de março de 1972, 14.607 casas do complexo do IAPI $^{3}$ foram desmontadas e seu moradores transferidos para Ceilândia (GDF, 1973). A vida no complexo do IAPI não era fácil: a precariedade das casas, o abastecimento de água por meio de torneiras coletivas, a falta de esgoto e a luz de motores impunham dificuldades, exigindo esforços na manutenção do dia a dia. Localizados nas proximidades do que hoje é o Núcleo Bandeirante, esses assentamentos apresentavam como vantagem sua proximidade ao Plano Piloto, lugar de concentração de trabalho e de serviços médicos. As escolas, à semelhança das habitações, eram edifícios frágeis, mas que cumpriam o propósito de oferecer educação às crianças. Havia nove escolas para um total de 5.729 alunos (GDF, 1973).

As difíceis condições de moradia parecem ter repercutido no convencimento da população do complexo do IAPI a se transferir para a nova cidade-satélite.

3. Segundo Oliveira (2007), o complexo era constituído por Vila do IAPI, Morro do Urubu, Morro do Querosene, Vila Tenório, Vila Bernardo Sayão, Vila Esperança, Curral das Éguas, Placa das Mercedes e outras. 
Pesava ainda, a favor da remoção, a promessa de propriedade de um lote individual em área legalizada. A remoção de 80 mil pessoas respaldou-se, portanto, no argumento da salubridade e na aspiração delas a uma vida melhor. Fortalecia a iniciativa governamental o Plano Diretor de Águas, Esgoto e Controle da Poluição (Planidro) de 1970, que determinava a construção da Estrada Parque do Contorno (EPTC), um anel envoltório ao Plano Piloto, cujos objetivos eram fornecer limites de ocupação urbana de forma a proteger a bacia hídrica do Paranoá (OLIVEIRA, 2007).

A transferência de tanta gente foi feita com método: houve cadastramento das famílias, as casas foram numeradas e orientações foram dadas para os desmontes, com a reutilização da madeira na construção de casas provisórias no novo destino. Aqueles que tinham condições de se deslocar por conta própria o fizeram. Outros, no entanto, dependiam do governo, que ofereceu caminhões para as mudanças. Marcada a data da remoção, duas equipes foram organizadas: o Grupo Executivo de Remoção (GER), responsável pelo desmonte das moradias da Vila do IAPI, e o Grupo Executivo de Consolidação (GEC), baseado em Ceilândia, que orientava a instalação dos que chegavam.

Para a obtenção da concordância dos moradores, aplicaram-se estratégias, como a descrita no relato de Francisca Coelho Pereira (FP, 2002, p. 9-10)4:

(SR) - Ninguém queria sair de lá para vim para cá?

(FP) - De jeito nenhum, então foi resolvido assim, primeiramente as igrejas, falaram lá, falaram com Avelino que os outros [...] aquele pastor... tinha o padre Liro, fazia parte também, aquele pastor... deixa eu ver se eu lembro, o pastor Joel, também fazia parte, tinha um outro reverendo também que fazia parte das reuniões.

$[\ldots]$

(FP) - Eu sei que combinaram com os pastores para reunir as igrejas, tirar primeiro as igrejas, vinha primeiro, para depois então tirar o povo.

(SR) - Que é uma forma também do povo acreditar.

(FP) - Acreditar.

(SR) - Que tem uma força espiritual.

(FP) - É, exatamente.

A chegada a Ceilândia também está registrada nas narrativas disponíveis no Arquivo Público do Distrito Federal:

(AS) Não era nada, só muita terra, lama na época da chuva e o resto era poeira. Poeira de ter hora assim da gente [...] nessa distância

4. Oliveira observou esse fato em sua dissertação de mestrado defendida no Departamento de Geografia da Universidade de Brasília em 2007. 
aqui ninguém enxergar uma à outra, não enxergava, porque não era poeira[,] era uma terra, tinha um vento roncador, ele fazia assim (vú, vú, vú, a gente ficava caçando se era avião, isso era o vento. (SILVA, 2002, p. 14) (DR) - A começar que tinha que limpar o terreno.

(DR) - Tinha uns toquinhos muito pequenininhos, mas nem se via por causa do cerrado.

(DR) - Demarcando, a gente tinha que limpar para construir, foi no mês de dezembro, chovendo demais.

(DR) - E nós ficamos onze dias debaixo de chuva (RODRIGUES, 2002, p. 9).

As memórias convergem quanto à falta de infraestrutura da nova cidade-satélite. Sem iluminação, rede de esgoto, água tratada e serviços de saúde, as pessoas lidavam com o dia a dia como podiam. Com candeeiros a querosene e luz a gás - as velas eram evitadas para impedir incêndios -, os ex-moradores da Vila do IAPI ressaltam que, entre as maiores dificuldades encontradas na iniciante Ceilândia, estava o acesso à água. Transportada por carros-pipa, era carregada em baldes para encher os tambores que ficavam em frente às casas. Segundo Ribeiro (2002, p. 9):

[...] a falta d'água, essa o maior terror da Ceilândia, as ruas escuras e a falta de asfalto, esgoto e uma série de outros benefícios não tinham chegado ainda à cidade, então a gente tinha que sair a tão [...] esse trabalho era feito pela Caesb [Companhia de Saneamento Ambiental do Distrito Federal], pela Secretaria de Serviços Sociais, pela Fundação, representada pelo CDS [Centro de Desenvolvimento Social], a gente tinha que correr atrás de caminhões-pipa pra encher esses chafarizes.

O esforço diário com os baldes de água e as contendas pelo roubo nos barris em frente às casas justificam a eleição da caixa-d'água de Ceilândia como atual patrimônio da cidade. Ela sintetiza o trabalho insano de sobrevivência dos moradores, assim como suas lutas políticas por reconhecimento. Antônia Alves da Silva (2002, p. 15-16) é um exemplo da peleja pela água:

Ah! minha filha, essa era a história mais séria, porque a gente botava os tamborzinhos lá fora, às vezes de oito em oito dias que o carro-pipa vinha colocar água, aquela água era ouro. Tinha mãe de família que banhava cinco, seis filhos numa bacia só, botava a aguinha ali, trazia o menino, começava pelo menorzinho, banhava o menorzinho[,] ia botando, chamando o segundo, o terceiro, o quarto, o quinto na mesma água [...].

Os núcleos de vizinhança da Vila do IAPI não foram considerados na transferência para a nova cidade, o que permite cogitar que os elos de solidariedade ali 
construídos foram desfeitos. Conforme a narrativa de Ilton Ferreira Mendes (IM, 2002, p. 14-15), não havia situações de privilégio, embora os lotes de esquina fossem destinados àqueles que exerciam atividades comerciais na Vila.

Um ponto a destacar: os lotes não foram doados aos moradores, mas adquiridos e pagos. Os valores inicialmente prometidos e depois reajustados deram origem ao movimento conhecido como Incansáveis de Ceilândia.

(IM) - No começo recebiam uma ordem de ocupação e eles ocupavam esse lote, depois esse lote foi vendido para as pessoas.

(SR) - Um preço simbólico.

(IM) - Foi vendido pelo preço da época, e eles só foram pagos muito tempo depois, inclusive houve muito problema na frente, como[,] por exemplo, nasceu a Associação dos Inquilinos aqui na Ceilândia. Nasceu por essa razão, porque alguns pagaram no começo o lote por um preço, quando os outros vieram a pagar já era um outro preço completamente diferente e[,] quando nós montamos essa questão da Associação dos Inquilinos, foi exatamente para garantir o preço que havia sido vendido na época.

O transporte e a locomoção das pessoas para os locais de trabalho foram outro drama. A escassez de ônibus e suas condições declaradamente obsoletas, com grandes buracos, não permitiam que os passageiros chegassem limpos à escola ou ao trabalho.

O início da Ceilândia parece confirmar a imagem de Eliade (1992) quando opõe a casa ao inquietante mundo de fora. As narrativas constroem uma representação de uma realidade inóspita e dura, um território bruto a ser construído e povoado.

\subsection{Casas do começo da cidade}

A ocupação de Ceilândia foi prevista para ocorrer em quatro etapas. A primeira delas consistia no recebimento do lote. A segunda, na edificação de moradia provisória no fundo do terreno de forma a deixar livre o espaço para a construção da casa definitiva, cuja realização definiria a terceira etapa. A quarta se completaria no desmanche das moradias provisórias. A ocupação da nova cidade-satélite em etapas justificou-se por estudos desenvolvidos à época, os quais consideravam o nível de renda dos moradores da Vila do IAPI.

A construção das casas provisórias na nova cidade parece ter sido frenética: “Aqui era assim, era noite e dia você ouvia era o som 'currutu, currut, currut', era serrote, martelo, 'pá, pá, pá' a noite inteira e o dia inteiro, um sai, ajudava o outro, o outro sai fazia mutirão” (BORGES, 2002, p. 12). Entre os moradores, havia aqueles que 
conseguiam montar suas casas rapidamente, enquanto outros dependiam de ajuda. Nesses casos, há menção a um padrão de construção mínima, com um único cômodo de $3 \mathrm{~m}$ x $4 \mathrm{~m}$, feita com material doado ou comprado: tábuas refugadas de pinho-do-paraná, vendidas por um preço simbólico. Essas tábuas, ao longo do tempo, tornavam-se esburacadas no lugar dos nós - Ilton Ferreira Mendes (2002) as compara a uma "tábua de pirulitos". As casas provisórias incluíam barracas de lona ou outros materiais precários, como papelão, sobre piso de chão batido. As descrições das casas provisórias reforçam a ideia de um quadro de apoio insuficiente para a população.

Em 1971, foi instalado na cidade o Escritório da Casa Própria (Ecap), subordinado ao Grupo Executivo de Consolidação da Ceilândia, com a função de facilitar a construção das casas em alvenaria, que deveriam tomar o lugar daquelas provisórias. O dono do lote poderia optar por um dos dois programas coordenados pelo Ecap. O primeiro deles, mais procurado (GDF, 1973), era a construção com recursos próprios, que oferecia vantagens, como a redução de taxas, a elaboração dos projetos de arquitetura e descontos para a compra de materiais. Segundo o Documento Ceilândia (GDF, 1973), vários moradores que escolheram esse programa tinham familiaridade com a construção civil, daí sua popularidade, pois ele possibilitava a construção das casas segundo a disponibilidade financeira do proprietário. Além disso, não exigia comprovação de renda, evitando endividamento junto às instituições financeiras.

O outro programa realizava-se por intermédio de financiamento pelo Banco Nacional de Habitação (BNH) via Sociedade de Habitação de Interesse Social (SHIS), vinculada à Secretaria de Serviços Sociais. Criada no ano de $1964^{5}$ e extinta em 1994, a SHIS era responsável pela construção de casas populares nas cidades do entorno do Plano Piloto, onde deixou suas marcas. No Guará, foram erguidas mais de 3 mil casas, entre outubro de 1967 e agosto de 1968. Em Ceilândia, segundo o GDF (1973), ficaram a cargo dessa Sociedade 1.300 lotes para a construção de dois conjuntos habitacionais e três conjuntos comerciais.

A fotografia de 1973 (Figura 5) mostra a área central de Ceilândia e o terreno onde hoje se localizam a Feira Central, a caixa-d'água e as casas da SHIS. É possível constatar a forma de ocupação dos lotes: as casas geminadas e as casas individuais com afastamentos nas duas laterais. Nota-se o destaque para as ruas de pedestres, ${ }^{6}$

5. A SHIS antecedeu a Sociedade de Habitações Econômicas de Interesse Social (SHEB), destinada a resolver o déficit habitacional mesmo antes da inauguração da nova capital.

6. Dos 2.670 becos em Ceilândia, segundo a Codhab, 111 estão desocupados e são áreas públicas, 259 são escriturados, e 436 foram beneficiados em 14 de janeiro de 2016. Disponível em: https://www.agenciabrasilia.df.gov.br/2016/01/14/436-lotes-em-becos-de-ceilandia-terao-escritura/. Acesso em: 10 out. 2020. 
que permitiam o movimento na transversal nas quadras. Os muros e o gabarito baixos afirmam uma fisionomia comum à maioria das cidades-dormitório que circundavam o Plano Piloto.

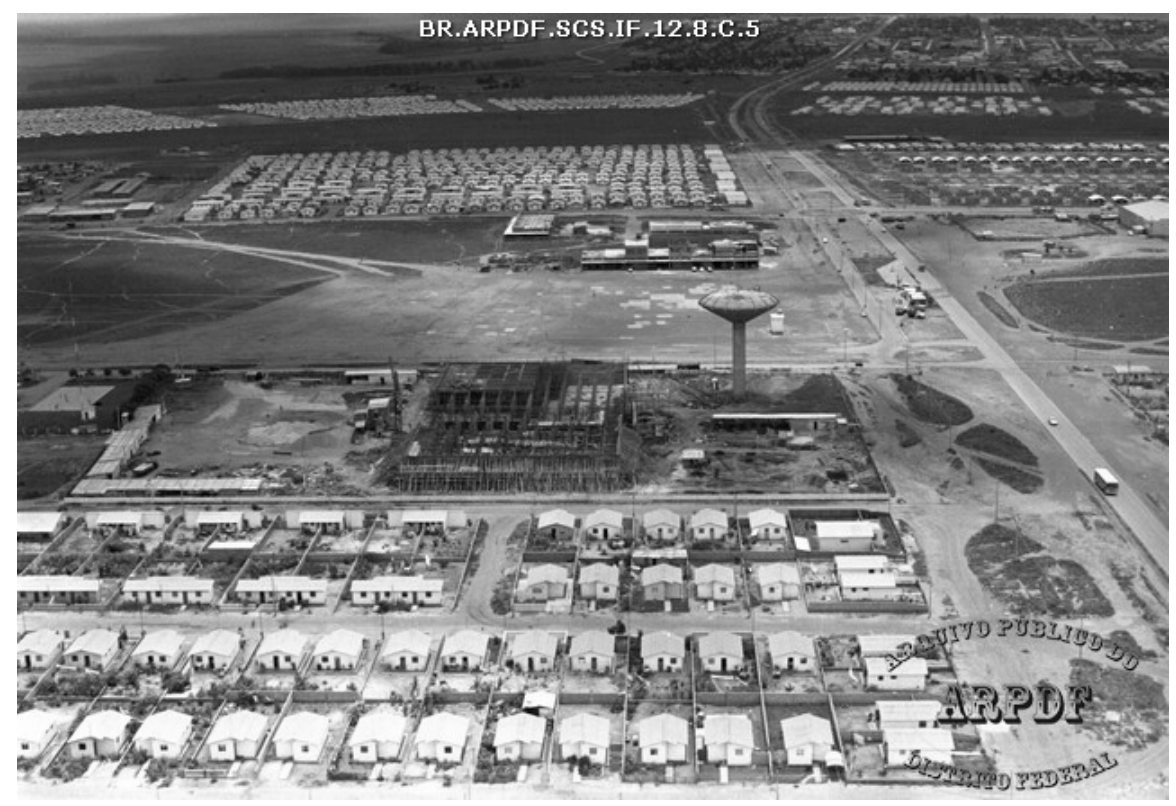

Figura 5. Vista aérea de Ceilândia

Fonte: Arquivo Público do Distrito Federal (2019).

A planta obtida junto à Administração Regional de Ceilândia (1976) mostra um padrão do que seria oferecido pela SHIS. Datada de 1976, ela apresenta um modelo com programa arquitetônico: são três quartos, um banheiro, cozinha e área de serviço. $\mathrm{O}$ afastamento frontal exigido é de no mínimo $3 \mathrm{~m}$, com afastamento lateral de 1,5 m em um dos lados. Na projeção da casa, sugerida na implantação por um desenho muito pouco detalhado, as dimensões são de 8,50 $\mathrm{m} \mathrm{x} \mathrm{8,0} \mathrm{m,} \mathrm{totalizando}$ $68,00 \mathrm{~m}^{2}$. Esse modelo arquitetônico poderia ser rebatido nos terrenos vizinhos de maneira a formar casas geminadas. A espessura das paredes indica o uso de alvenaria e a cobertura em telha de fibrocimento, que se pode deduzir em decorrência da pequena inclinação apresentada nos cortes (Figura 6).

A tipologia de habitação da SHIS pode ser considerada como um segundo momento de Ceilândia e de suas moradias, definido pela paulatina substituição das casas provisórias. Poucas casas no padrão SHIS chegaram aos dias atuais em sua versão original. 

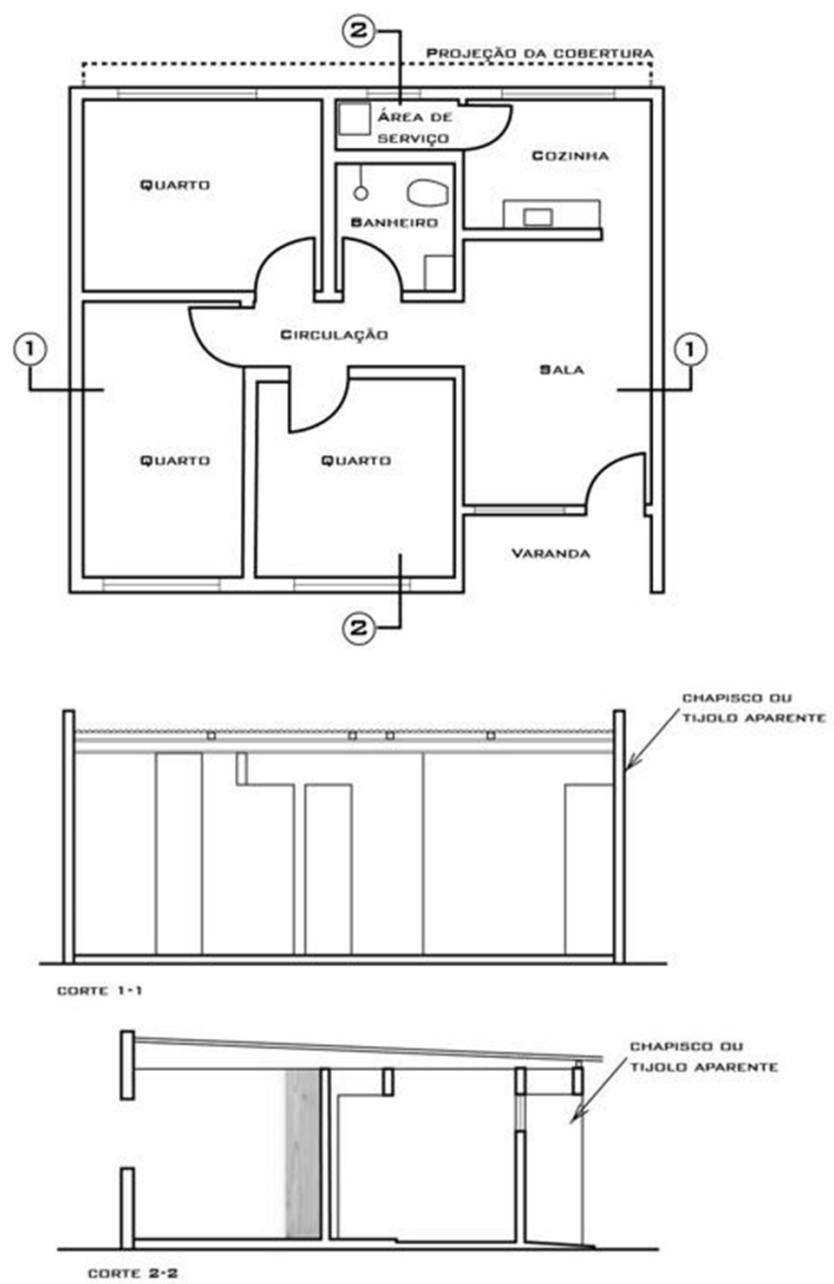

Figura 6. Planta e corte do modelo habitacional SHIS

Fonte: Redesenho de Alana Waldvogel com base em planta fornecida pela Administração Regional de Ceilândia.

\section{Casas de hoje}

Para falar das casas atuais de Ceilândia, recorremos a documentos de três naturezas. A primeira delas é formada por um levantamento realizado nas quadras QNM17 e QNM18, localizadas na Ceilândia Tradicional, a parte mais antiga da cidade projetada por Ney Gabriel. O intuito era constatar a ocupação dos lotes, de forma a conferir o número de moradias em cada um. Tomaram-se, para esse objetivo, as bases cartográficas da Segeth, atualizadas com o auxílio de imagens de satélite, disponíveis nas plataformas Google Maps (2019) e Google Earth (2019). Muitos lotes, quando comparados às imagens dessas plataformas, revelam o desaparecimento dos recuos e uma taxa de ocupação de 100\% (Figura 7). 


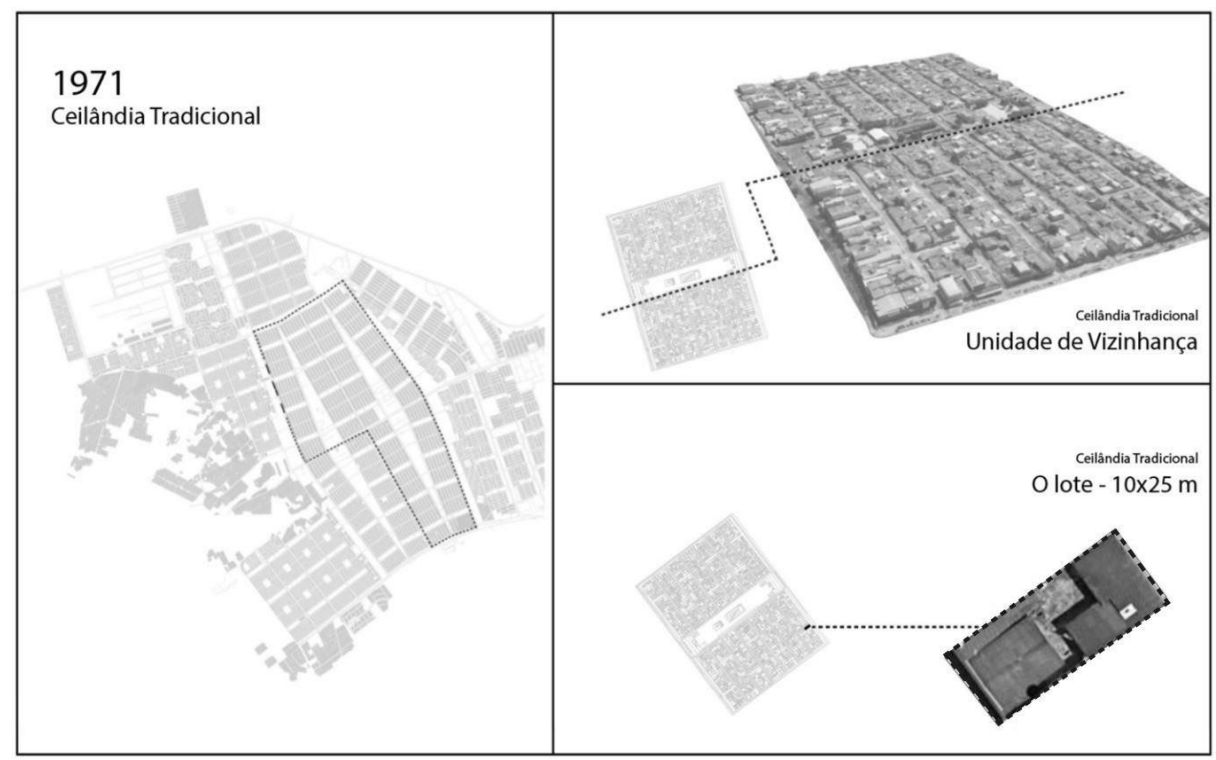

Figura 7. Exemplo de levantamento feito dos setores de Ceilândia

Fonte: Base cartográfica Segeth, imagem de satélite do Google Maps (2019). Catalogação, levantamento e atualização de Alana Waldvogel.

A atualização efetuada não permitiu, na sua totalidade, concluir sobre o número de casas construídas em cada lote. Para esclarecer a questão, fomos a campo para averiguar a presença de mais de uma moradia por terreno baseando-nos nos medidores de água, fato confirmado por dados da Caesb, conforme aponta a Tabela 1.

\begin{tabular}{c|c|c|c} 
& Lotes & $\begin{array}{c}\text { Unidades } \\
\text { Consumidoras (UCs) }\end{array}$ & Média de UCs por lote \\
\hline QNM 17 & 326 & 1.125 & 3,45 \\
\hline QNM 18 & 330 & 934 & 2,83 \\
\hline
\end{tabular}

Tabela 1. Relação do número de lotes por quadras/Unidades Consumidoras Fonte: Dados da Caesb. Tabela elaborada por Alana Waldvogel.

A segunda natureza dos documentos consultados compôs-se de relatos e desenhos das casas elaborados pelos alunos do $9^{\circ}$ ano do Centro de Ensino Fundamental (CEF) 19 de Ceilândia, frutos de atividades propostas pela pesquisa "Cotidianos Escolares e Dinâmicas Metropolitanas da Capital do Brasil”, de cuja equipe fazemos parte.

7. A pesquisa “Cotidianos Escolares e Dinâmicas Metropolitanas da Capital do Brasil”, financiada pela FAP-DF, reúne antropólogos e arquitetos voltados ao estudo da capital federal considerada em sua dimensão metropolitana. A essa pesquisa interessava entender, sob os pontos de vista espacial e vivencial, os deslocamentos cotidianamente empreendidos pelos habitantes de Brasília, cidade fragmentada e dispersa entre o Plano Piloto de Lucio Costa e suas Regiões Administrativas. 
Os relatos foram colhidos durante o ano de 2018 e consistiram em um exercício no qual os alunos descreviam suas moradias. É importante mencionar que os alunos não são moradores das quadras cartografadas, mas, apesar disso, ofereceram uma noção do morar em Ceilândia. Guarda-se o anonimato das descrições reproduzidas ${ }^{8}$ a seguir.

\begin{abstract}
Relato 1
Minha casa tem muito espaço. Tem um barraco de fundo onde a gente aluga para um casal. A cozinha tem espaço ideal. Por ter duas salas, nunca tem briga para assistir TV ou jogar videogame. [...] $\mathrm{O}$ meu quarto tenho que dividir com meu irmão e as minhas irmãs dividem o delas. Essa casa é da minha avó e do meu avô, então meus tios, filhos deles, moravam lá na época da construção de Brasília.
\end{abstract}

\title{
Relato 2
}

Onde moro tem duas casas em um lote. Na casa da frente, a principal, mora eu, meu pai e meu avô. Na casa dos fundos, mora minha prima. Essa casa está na minha família desde 1980. O meu avô, que é engenheiro aposentado, fez algumas modificações na casa.

\section{Relato 3}

Onde eu moro é um lote, ele tem 6 barracos. Eu morava lá na última casa. Morei neste barraco até meus 11 anos, depois fomos para outro barraco. Por que mudamos? Porque estava caro o aluguel. [...] Meu tio mora com a gente [...] Nesse barraco tem 1 quarto, 1 cozinha, 1 sala e 1 banheiro. A sala e a cozinha é americana.

\section{Relato 4}

[...] tenho 14 anos e moro em Ceilândia, moro em uma casa grande, pois só moram 3 pessoas comigo: meu pai, minha mãe e eu. Lá tem 1 banheiro, 2 quartos, 1 sala, 1 cozinha e 1 garagem.

\section{Relato 5}

Bem, eu moro aqui faz 14 anos, [...] porém já tiveram várias alterações na minha casa. Antes, era casa de fundo, [...] fizeram um quarto improvisado para mim durante um tempo, e aí, minha casa tem uma loja atrás, [...] a loja fica de frente para a rua; [...] Por isso desalugaram os fundos e fizeram um quarto e outro suíte. Só que minha mãe queria fazer um salão e, para isso, tinha que pegar o quarto da frente pra salão, ou seja: sobraram 2 quartos + o quarto improvisado. Eu precisava de um quarto, porque eu já tava grandinha e, então, fizeram um quarto na frente e, agora, tá parecendo uma casa normal, porque antes não parecia.

8. Os textos foram mantidos quase na íntegra. Apenas pontuação e correções ortográficas foram feitas. Os grifos são nossos. 


\section{Relato 6}

[...] moro aqui desde que nasci [...] Onde moro, tem muitas pessoas, é uma casa até que grande: 4 quartos, 1 banheiro, sala e cozinha - que, na verdade, se torna pequena, pois moram outras 5 pessoas comigo: meu avô, minha avó, minha mãe, meu irmão e meu tio. Na casa dos fundos, moram mais 9 pessoas. É uma casa de andar, a casa dos fundos, mas menor. Lá moram minha tia, o marido da minha tia, as duas filhas dela, em cima; e, embaixo, moram minha tia e seus 3 filhos.

\section{Relato 7}

Não sei a história da casa onde moro, mas ela é a melhor desde quando mudei para Brasília. Onde moro são 3 apartamentos, e minha relação com os vizinhos não existe. Bom, não existe porque não conheço nenhum.

\section{Relato 8}

A minha casa começou a ser construída na década de 80. Aqui na minha rua não tinha nem asfalto, ela foi construída por meu tio-avô [...]. No começo, a minha casa tinha um andar. Posteriormente, meu tio-avô construiu andares e alugou o primeiro e se mudou para o segundo e construiu o terceiro (lavanderia).

Somam-se a esses relatos os desenhos de estudantes da mesma escola feitos em 2019, descortinando pistas importantes sobre o morar em Ceilândia. A expectativa com a proposição aos estudantes de que desenhassem suas moradias era de entrever, com um pouco mais de detalhe, suas divisões e seu funcionamento. Para isso, foi preparada uma ficha com papel milimetrado, na esperança de que uma relação de proporção pudesse ser observada. Explicamos aos estudantes como uma planta de arquitetura é elaborada. Nem todos os alunos realizaram os trabalhos: foram dez os contabilizados e classificados, considerando os ambientes presentes e o número de residências construídas nos lotes. Alguns desses desenhos continham informações sobre o leiaute, com amostragem de mobiliário e equipamentos (Figura 8).

O conjunto desses desenhos e relatos fornece elementos para a identificação da materialidade das casas e indica parâmetros sociais, caracterizados pelas formas de morar dos ceilandenses. Na Tabela 2 apresenta-se um compilado desses dados. 

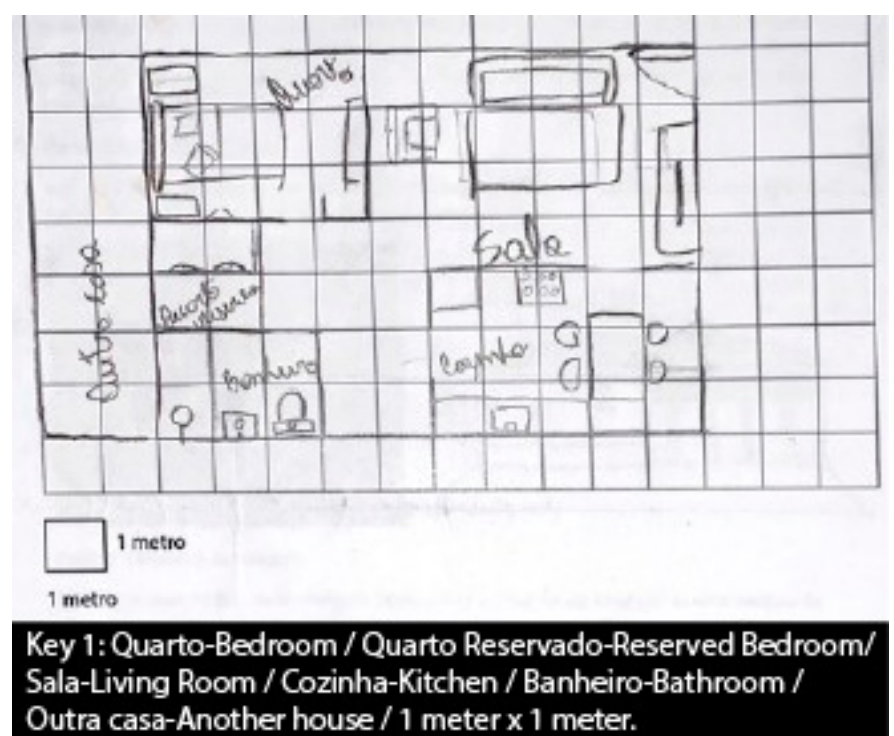

Outra casa-Another house / 1 meter x 1 meter.
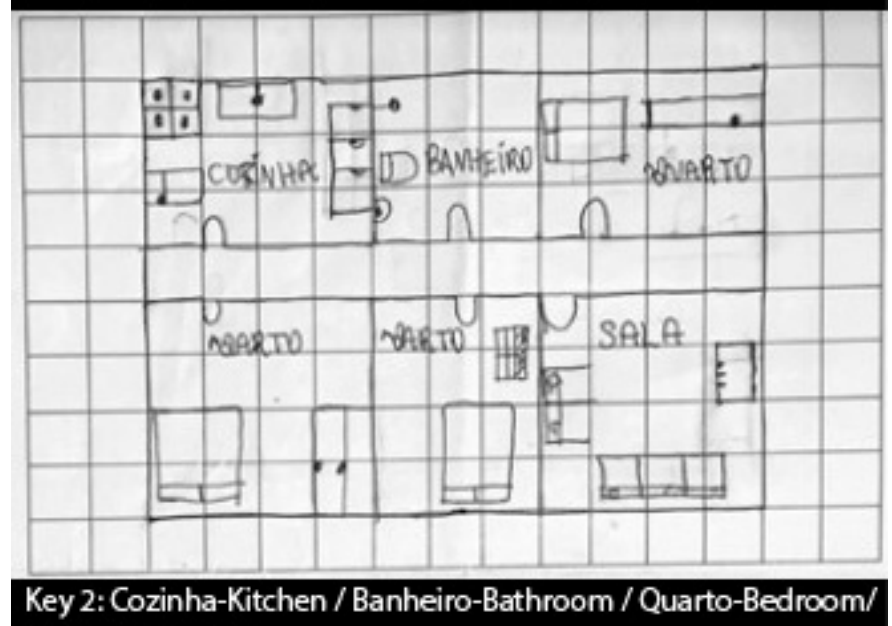

\section{Sala-Living Room.}

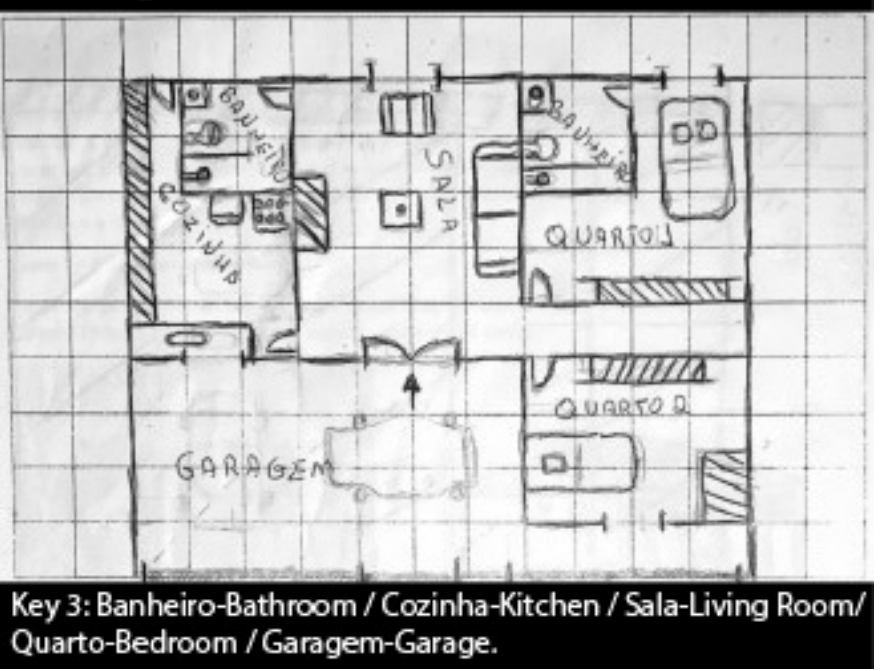

Figura 8. Desenhos de estudantes do CEF 19

Fonte: Pesquisa "Cotidianos Escolares e Dinâmicas Metropolitanas da Capital do Brasil" (2018-2019). 


\begin{tabular}{|c|c|c|c|c|c|c|}
\hline & Garagem & Quartos & $\begin{array}{l}\text { Área de } \\
\text { serviço }\end{array}$ & Suíte & $\begin{array}{l}\text { Ocupação } \\
\text { do lote }\end{array}$ & Observações \\
\hline Casa 1 & $\operatorname{sim}$ & 3 & $\operatorname{Sim}$ & Não & +2 casas & \\
\hline Casa 2 & Não & 3 & Não & Não & +1 casa & Churrasqueira \\
\hline Casa 3 & Não & 3 & Sim & Não & +1 casa & $\begin{array}{c}\text { Duas salas, divide o quarto } \\
\text { com outros moradores; casa } \\
\text { de pioneira }\end{array}$ \\
\hline Casa 4 & Não & 1 & Sim & Não & +3 casas & \\
\hline Casa 5 & Não & 3 & Sim & Sim & $\begin{array}{c}\text { Casas para } \\
\text { aluguel }\end{array}$ & $\begin{array}{c}\text { Sala com cozinha americana, } \\
\text { varanda, andar (escada) }\end{array}$ \\
\hline Casa 6 & Não & 3 & $\operatorname{Sim}$ & Não & - & 2 salas (TV, visitas) \\
\hline Casa 7 & Não & 2 & Não & Não & +1 casa & \\
\hline Casa 8 & Não & 2 & Não & Não & +3 casas & \\
\hline Casa 9 & $\operatorname{sim}$ & 2 & Não & Sim & Não & \\
\hline Casa 10 & Sim & 2 & $\operatorname{Sim}$ & Sim & Não & \\
\hline
\end{tabular}

Tabela 2. Casas e cômodos identificados na Pesquisa "Cotidianos Escolares e Dinâmicas Metropolitanas da Capital do Brasil" (2018-2019)

Fonte: Elaborada pelas autoras.

Com base nos documentos apresentados, é possível afirmar a constante frequência de mais de uma moradia no mesmo lote, o que pôde ser identificado por meio dos levantamentos efetuados nas quadras QNM17 e QNM18, bem como dos dados da Caesb (2019), e confirmado pelos relatos destacados e pelos desenhos feitos pelos alunos do CEF 19. Essa situação se explica pelos arranjos que as famílias criaram em Ceilândia e que não são distintos dos encontrados em outras cidades e seus bairros de trabalhadores. Ora as casas se alteram no tempo para abrigar uma família que cresce, ora se modificam para atender às necessidades de renda, via aluguel ou prestação de serviços. Nesses arranjos, as configurações são múltiplas, ainda que em lotes pequenos: há casas que crescem na vertical, com a construção de pavimentos; há a presença de duas ou mais casas em um mesmo lote, entre outras possibilidades. As vozes dos adolescentes não expressam estranhamento diante dessa situação, pois ela é parte de sua vida cotidiana (Figura 9).

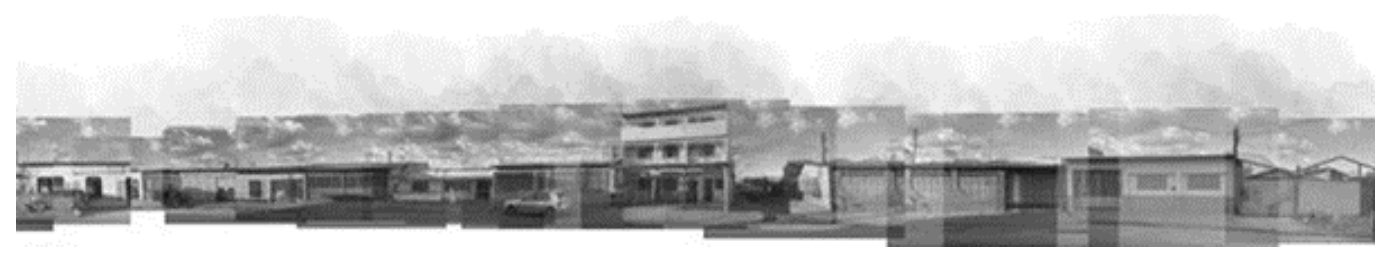

Figura 9. Fachadas de casas em Ceilândia Fonte: Alana Waldvogel (2019). 
Sobre a percepção da casa em si, verifica-se nos relatos uma distinção entre casa e barraco que é importante assinalar. Ao se referir a uma moradia que compartilha o espaço com outras em um mesmo lote, parece ser comum o termo barraco, enquanto o termo casa assume uma condição de moradia melhor. O barraco sugere uma possível precariedade, ausente na sólida imagem da casa. O primeiro termo é muito utilizado em Goiás e faz referência a uma construção de telhado de meia-água, localizada sem afastamentos de uma ou mais divisas do terreno, assemelhando-se a uma edícula de serviços, mas, por vezes, com função de moradia.

As divisões das moradias correspondem, com grau maior de flexibilidade, ao zoneamento funcional tripartite - serviço, área social e íntima. Sem a ortodoxia da casa burguesa, os arranjos das residências podem resultar em aberturas de portas de quarto ou mesmo a de banheiros para salas. Na avaliação da materialidade dessas casas, garagens e suítes não são comuns e aparecem, simultaneamente, em unidades sem compartilhamento do lote, sugerindo a especialização dos usos de alguns espaços. Da mesma forma, tanto por meio dos relatos como dos desenhos, nota-se a sobreposição de algumas atividades em determinados ambientes, como salas e quartos, onde se joga videogame, se fazem refeições e se recebem visitas. Para um, a cozinha tem tamanho ideal, o que deve significar que cabem todos os mobiliários e equipamentos. Para outro, é importante ressaltar que a cozinha é americana, numa referência à abertura desse cômodo para a sala.

Chama atenção a presença de uma casa na mesma família, em que ela se constitui em um bem transmitido de avós e pais para filhos, ou o compartilhamento delas por famílias expandidas. Nesse sentido, os depoimentos insinuam a casa como um local de força (ASSMANN, 2011), de transmissão de memórias, pelo simples fato da extensão e da longevidade de sua existência. Da mesma maneira, é possível entrever relações familiares e próximas entre os moradores de um mesmo lote, o que possibilitaria inferir a formação de uma teia de interdependência.

Os relatos e os desenhos expressivos dos adolescentes não dizem tudo. Todavia, contam algo do seu morar. O morar que expressam suas vidas, mas também o morar daqueles que vieram antes e, entre outras dificuldades, enfrentaram animais e poeira. 


\section{Para terminar o que não tem fim}

A memória é uma paisagem contemplada de um comboio em movimento. Vemos crescer por sobre as acácias a luz da madrugada, as aves debicando a manhã, como a um fruto. Vemos, além, um rio sereno e o arvoredo que o abraça. Vemos o gado passando lento, um casal que corre de mãos dadas, meninos dançando o futebol, a bola brilhando ao sol (um outro sol). Vemos os lagos plácidos onde nadam os patos, os rios de águas pesadas onde os elefantes matam a sede. São coisas que ocorrem diante dos nossos olhos, sabemos que são reais, mas estão longe, não a podemos tocar. Algumas estão tão longe, e o comboio avança veloz, que não temos a certeza de que realmente aconteceram. José Eduardo Agualusa (2018), O vendedor de passados.

A Ceilândia de 2020 é muito distinta daquela dos anos 1970. Seu passado lembra as imagens que Agualusa (2018) descreve na viagem do "comboio" tempo. Fugazes, elas se sucedem na velocidade do movimento e deixam dúvidas sobre sua real existência. Buscou-se neste artigo criar uma possibilidade de entrever Ceilândia por meio de múltiplas imagens, com base em seu começo e em sua condição atual. De cidade periférica, ela desequilibra, hoje, o jogo demográfico do Distrito Federal, concentrando a maior parte de sua população. É um centro consolidado de referência e de produção cultural - grupos de rap, o hip-hop, o cinema e as festas juninas são expressões indissociáveis dessa cidade.

Apesar disso e de todas as modificações que seus moradores promoveram, de suas conquistas e do orgulhoso sentimento de pertencimento, as diferenças sociais de seus moradores com aqueles do Plano Piloto são, sem dificuldades, expressas nos espaços urbanos e nas moradias. Na imensa mancha urbana constituída pela metrópole brasiliense, o plano de Lucio Costa assemelha-se aos paraísos dos condomínios fechados. O muro a separá-lo da cidade real é seu perímetro de tombamento. Nesse fragmento pouco representativo da totalidade da cidade, acontece um evento que pode ilustrar a fratura entre Plano Piloto, Ceilândia e outras cidades-satélites. Em determinados finais de semanas, promove-se um evento denominado "Chef nos Eixos". Nesses dias, cozinhas e barracas são montadas no Eixo Rodoviário para comercializar pratos elaborados por chefs a preços acessíveis. Há pratos abrangendo as culinárias brasileira e estrangeira - bobó de camarão, carbonara no queijo, frango envolto em fondue de queijo gruyère, a título de exemplo. Na Feira Central de Ceilândia, todavia, os pratos servidos são outros: fervem, nas imensas panelas de seus restaurantes, a rabada com agrião, o sarapatel, a buchada. Os cardápios comparados mostram cidades postas em paralelo e que dificilmente se comunicam. Como construir elos capazes de conectar esses mundos? 
Esse distanciamento também é perceptível nas casas. Se, no Plano Piloto, os apartamentos ou as casas abrigam, genericamente, uma família, nas moradias ceilandenses esse universo é compartilhado entre as gerações de uma mesma família ou com estranhos que alugam algum quinhão desses espaços. A construção de histórias individuais do Plano Piloto se defronta com o compartilhamento de memórias advindas de experiências que se sedimentam em lugares de densidade afetiva, como as casas compartilhadas. As dificuldades da existência não impedem que os laços identitários sejam tecidos e refletidos nas casas e na vida dos moradores. Os desenhos e relatos de adolescentes indicam respeito a um jeito de ser, sem serem inconformados ou submissos. Esse material registra a memória de pessoas jovens, mas que constroem a sua história, encadeando a própria trajetória às dos seus pais e avós.

\section{Referências}

ADMINISTRAÇÃO REGIONAL DE CEILÂNDIA. Arquivo: Plantas residenciais da Sociedade de Habitação de Interesse Social (SHIS). Brasília: DF, 1976.

ARQUIVO PÚBLICO DO DISTRITO FEDERAL. Imagens diversas. Brasília, DF: Ministério da Justiça e Segurança Pública, 2019.

AGUALUSA, J. E. O vendedor de passados. São Paulo: Tusquets, 2018. p. 157.

ASSMANN, A. Espaços de recordação: formas e transformações da memória cultural. Tradução: Paulo Soethe. Campinas: Ed. da Unicamp, 2011.

BACHELARD, G. A poética do espaço. Tradução: Antônio de Pádua Danesi. São Paulo: Martins Fontes, 1996.

BENJAMIN, W. Sobre o conceito de história. In: BENJAMIN, W. Magia e técnica, arte e política: ensaios sobre literatura e história da cultura. Tradução: Sérgio Paulo Rouanet. 7. ed. São Paulo: Brasiliense, 1994. v. 1. (Obras escolhidas).

BORGES, M. L. Depoimento. Programa de História Oral. Brasília: Arquivo Público do Distrito Federal, 2002.

BRESCIANI, S. Verbete casa. In: TOPALOV, C.; BRESCIANI, S.; LILLE, L. de; D’ARC, H. R. (org.). A aventura das palavras da cidade: através dos tempos, das línguas e das sociedades. São Paulo: Romano Guerra, 2014. p. 174-183.

COMPANHIA DE SANEAMENTO AMBIENTAL DO DISTRITO FEDERAL (CAESB). Fornecimento de dados. Brasília, DF: Caesb, 2019.

COSTA, G. G. da. As Regiões Administrativas do Distrito Federal de 1960 a 2011. 2011. Tese (Doutorado) - Faculdade de Arquitetura e Urbanismo da Universidade de Brasília, Brasília, DF, 2011.

COUTO, M. Um rio chamado tempo, uma casa chamada terra. São Paulo: Companhia das Letras, 2003. p. 27. 
DAMATTA, R. O que faz o brasil, Brasil? 12 ed. Rio de Janeiro: Rocco, 2001.

A casa \& a rua: Espaço, cidadania, mulher e morte no Brasil. Rio de Janeiro: Guanabara Koogan, 1991.

DERNTL, M. F. História, memória e patrimônio de Brasília: escolas em unidades de vizinhança. In: MOURA, C. P. de; PEIXOTO, E. R.; DERNTL, M. F. Cotidianos, escolas e patrimônio: percepções antropo-urbanísticas da capital do Brasil. Brasília: UnB, 2020 (no prelo).

ELIADE, M. O sagrado e o profano. Tradução: Rogério Fernandes. São Paulo: Martins Fontes, 1992.

GOVERNO DO DISTRITO FEDERAL (GDF). Documento Ceilândia. Brasília, DF: GDF, 1973.

GOOGLE. Google Earth website. Disponível em: https://www.google.com.br/intl/pt-BR/earth/ Acesso em: out. 2019.

Google Maps. Disponível em: https://www.google.com.br/maps/@-15.8144964,$-47.9096315,711 \mathrm{~m} /$ data=!3m1!1e3. Acesso em: out. 2019.

HOLSTON, J. A cidade modernista: uma crítica de Brasília e sua utopia. São Paulo: Companhia das Letras, 2010.

JEUDY, H.-P. Liberdade da memória: uma entrevista com Henri-Pierre Jeudy. Revista Pós, São Paulo, n. 15, p. 10-15, 2004.

MENDES, I. F. Depoimento. Programa de História Oral. Brasília, DF: Arquivo Público do Distrito Federal, 2002.

OLIVEIRA, T. M. G. A erradicação da Vila do IAPI: marcas do processo de formação do espaço urbano de Brasília. 2007. Dissertação (Mestrado) - Departamento de Geografia da Universidade de Brasília, Brasília, DF, 2007.

PEREIRA, F. C. Depoimento. Programa de História Oral. Brasília: Arquivo Público do Distrito Federal, 2002.

RIBEIRO, E. M. Depoimento. Programa de História Oral. Brasília: Arquivo Público do Distrito Federal, 2002.

RIGOTTI, G. Urbanismo: la técnica. Tradução para o espanhol: Francisco Folgueira. Barcelona: Madrid: Rio de Janeiro: Editorial Labor, 1955.

RODRIGUES, D. A. N. Depoimento. Programa de História Oral. Brasília, DF: Arquivo Público do Distrito Federal, 2002.

SECRETARIA DE ESTADO DE GESTÃO DO TERRITÓRIO E HABITAÇÃO (SEGETH). Plantas urbanas e imagens aéreas. Brasília, DF: GDF, 2019. Disponível em: https://www.geoportal. seduh.df.gov.br/mapa/. Acesso em: out. 2019.

SEIXAS, J. A. Percursos da memória em terras da História: problemáticas atuais. In: BRESCIANI, S.; NAXARA, M. (org.). Memória e (res)sentimento: indagações sobre uma questão sensível. Campinas: Ed. da Unicamp, 2001.

SILVA, A. A. da. Depoimento. Programa de História Oral. Brasília, DF: Arquivo Público do Distrito Federal, 2002. 


\section{Elane Peixoto}

Arquiteta e urbanista, mestre e doutora pela Faculdade de Arquitetura e Urbanismo da Universidade de São Paulo (FAU-USP), com estágio na Maison des Sciences de l'Homme, Paris, França. Professora da Faculdade de Arquitetura e Urbanismo da Universidade de Brasília (UnB) e de seu Programa de Pós-graduação, atuando nas linhas de pesquisa da História e Teoria da Cidade, assim como da História e Teoria da Arquitetura e Patrimônio e Preservação. Em 2015, foi professora visitante na Università Iuav di Venezia.

Email: elane@unb.br

ORCID: 0000-0001-9998-3438

Contribuição de autoria: conceituação; curadoria de dados; investigação/pesquisa; metodologia; escrita - primeira redação; escrita - revisão e edição.

\section{Adriana Mara Vaz de Oliveira}

Arquiteta e urbanista, mestre e doutora em História, respectivamente pela Universidade Federal de Goiás (UFG) e pela Universidade Estadual de Campinas (Unicamp). Professora do curso de Arquitetura e Urbanismo e do Programa de Pós-graduação Projeto e Cidade da Faculdade de Artes Visuais da UFG, atuando na linha de pesquisa História e Teoria da Arquitetura e da Cidade.

Email: amvoliveira@ufg.br

ORCID: 0000-0002-4014-0003

Contribuição de autoria: conceituação; escrita - primeira redação; escrita - revisão e edição. 


\section{Alana Silva Waldvogel}

Arquiteta graduada pela Universidade de Brasília (UnB), onde atualmente realiza mestrado em Teoria e História do Urbanismo. Desde 2016 tem como foco de pesquisa a cidade de Ceilândia, sua formação e morfologia urbana. Atuou como pesquisadora bolsista pela CNPq e pela FAP-DF, além de ter trabalhado no Instituto do Patrimônio Histórico e Artístico (Iphan-DF) durante a graduação.

Email: alana_waldvogel@hotmail.com

ORCID: 0000-0002-5410-5321

Contribuição de autoria: conceituação; curadoria de dados; investigação/pesquisa; metodologia; escrita - primeira redação.

Submissão: 3 de agosto de 2020.

Aprovação: 16 de novembro de 2020.

Como citar: PEIXOTO, E.; OLIVEIRA, A. M. V.; WALDVOGEL, A. S. As casas de Ceilândia. Revista brasileira de estudos urbanos e regionais. V. 23, E202104pt, 2021. DOI 10.22296/23171529.rbeur.202104pt

Artigo licenciado sob Licença Creative Commons CC BY 4.0. https://creativecommons.org/licenses/by/4.o/deed.pt_BR 